Revista Iberoamericana. Vol. LXV, Núm. 187, Abril-Junio 1999; 263-264

\title{
EROTISMO Y ESCRITURA: INTRODUCCIÓN
}

Hace diez años un título como el de este número habría hecho pensar en la visión de la escritura erótica de Octavio Paz (y de Georges Bataille): celebratoria, algo abstracta, inevitablemente heterosexual y misógina. La lectura de los artículos que siguen sugiere nuevas maneras de llegar al nexo entre Eros y textualidad. Bataille y Paz sí se citan en estos trabajos, pero junto a una serie de pensadores que han reflexionado sobre las exclusiones que practicaban los pensadores hegemónicos y heterosexistas: Foucault, Butler, Edelman, Sedgwick, Rich y Molloy son algunos de los nombres que se citan a menudo en lo que sigue.

La preparación de este número, y del libro (Sexualidad y nación en América Latina) que lo acompaña, permite ver algunas modas o tendencias en la crítica actual. Cuando se mandó la circular anunciando el número especial de la Revista Iberoamericana a los socios del Instituto Internacional de Literatura Latinoamericana, llovieron propuestas, algunas sobre autores poco conocidos, otros sobre figuras famosas, pero no siempre lo que se habría podido imaginar. Habría podido hacer un número apenas sobre tres o cuatro de los nombres más frecuentados: Manuel Puig, Virgilio Piñera, Reinaldo Arenas, Sylvia Molloy. Sobre Cortázar y Paz llegó poco.

Es motivo de celebrar que los estudios de la literatura latinoamericana se hayan abierto ahora de modo definitivo a las reflexiones del Queer Theory, hasta el punto que se piensa la heterosexualidad, no simplemente se acepta como algo que da por sentado (ver estudios aquí de López Cruz, Epple, García Calderón). El travestismo que tanto intrigó a Carpentier en 1931 (según nos revela Cancio) y a Donoso en 1967 (véase trabajo de Ostrov) se asocia ahora al acto de escribir: tanto en las reflexiones de Kuhnheim sobre Perlongher como en las de Ostrov sobre Donoso, el que escribe asume ese disfraz ambiguo que tanto horrorizó — ¿y fascinó? - a Carpentier. Y la "homotextualidad" se explora en sus matices femeninos en los trabajos de Martínez, Ferreira Pinto y García Calderón.

Virgilio Piñera escribió en 1955, en su ensayo "Ballagas en persona":

Si los franceses escriben sobre Gide tomando como punto de partida el homosexualismo de este escritor; si los ingleses hacen lo mismo con Wilde, yo no veo por qué los cubanos no podemos hablar de Ballagas en tanto que homosexual. ¿Es que los franceses y los ingleses tienen la exclusiva de tal tema? (Poesía y crítica, 194). 
Más de cuarenta años después, la Revista Iberoamericana abre espacios para reflexiones que quitan a los franceses, ingleses y compañía esta exclusiva, y demuestran la importancia de vincular el estudio de la sexualidad — en toda su diversidad - al de la literatura latinoamericana, para acabar con lo que Borges llamó (en otro contexto) el "pudor de la historia".

Daniel BaLderston

University of lowa 